\title{
RESGATE HISTÓRICO PARA O BUTIÁ DE BONPLAND, BUTIA NOBLICKII DEBLE, MARCHIORI, F.S. ALVES \& A.S. OLIVEIRA, ARECACEAE DA PROVINCIA DE CORRIENTES, ARGENTINA ${ }^{1}$
}

\author{
JOSÉ NEWTON CARDOSO MARCHIORI ${ }^{2}$
}

\section{RESUMO}

Com base em edição facsimilar dos manuscritos de Aimé Bonpland, verificou-se que Butia Noblickii, palmeira recentemente descrita, já era reconhecida pelo grande botânico francês como espécie distinta de Butia yatay.

Palavras-chave: Aimé Bonpland, Arecaceae, Butia Noblickii, Butia yatay, butiá de Bonpland.

\section{ABSTRACT}

[An historical rescue to Bonpland's palm tree, Butia Noblickii Deble, Marchiori, F.S. Alves \& A.S. Oliveira, Arecaceae from Corrientes province, Argentina].

Based on a facsimile edition of Aimé Bonpland's manuscripts, it was verified that Butia Noblickii, a palm tree recently described, was previously recognized by the great French botanist as a distinct species from Butia yatay.

Key words: Aimé Bonpland, Arecaceae, Bonpland’s palm tree, Butia Noblickii, Butia yatay.

\section{INTRODUÇÃO}

A espécie formadora do palmar que se estende à margem direita do rio Uruguai desde as proximidades de Yapejú ${ }^{3}$ até Bonpland ${ }^{4}$, na província argentina de Corrientes, era até poucos anos atrás ${ }^{5}$ confundida com Butia yatay (Mart.)

1 Recebido em 05-10-2014 e aceito para publicação em 26-02-2015.

2 Engenheiro Florestal, Dr. Bolsista de Produtividade em Pesquisa (CNPq - Brasil). Professor Titular do Departamento de Ciências Florestais, Universidade Federal de Santa Maria.marchiori@pq.cnpq.br

3 Ocupando o sítio da antiga redução jesuítica de Nuestra Señora de los Santos Reyes Magos de Yapejú, fundada em 4 de Fevereiro de 1627, Yapejú é, atualmente, o nome de uma localidade e município do Departamento de San Martín, na província de Corrientes $\left(29^{\circ} 28^{\prime} 00^{\prime \prime S}\right.$ $\left.56^{\circ} 50^{\prime} 00^{\prime \prime O}\right)$. Berço natal do prócer argentino José de San Martín, a localidade dista $395 \mathrm{~km}$ da capital provincial (Corrientes), e fica à margem direita do rio Uruguai, entre Paso de los Libres e Alvear (cidade em frente à gaúcha Itaqui), ao sul da foz do rio Ibicuí, afluente da margem esquerda do rio Uruguai.

4 Atualmente, Bonpland é nome de uma localidade (2949’03"S $57^{\circ} 25^{\prime} 40^{\prime \prime O}$ ) e município do departamento de Paso de los Libres. É em terras desse município do sudeste da província de Corrientes que ficava a "Estância Santa Ana”, de Aimé Bonpland, bem como o limite austral de distribuição geográfica de Butia Noblickii.

5 Trata-se de Butia Noblickii, espécie descrita no seguinte artigo desta mesma revista: DEBLE, L.P.; MAR-
Becc., Arecaceae de ampla distribuição na Mesopotâmia argentina e oeste do Uruguai. O presente artigo visa a demonstrar, com base em fragmentos literários pouco conhecidos, que o butiá de Bonpland (Butia Noblickii Deble, Marchiori, F.S. Alves, A.S. Oliveira) já era considerado espécie distinta por Aimé Bonpland, um dos mais importantes botânicos da primeira metade do século dezenove, e que viveu os últimos quarenta e um anos de sua vida na Argentina, Paraguai e Rio Grande do Sul.

Para a abordagem dos referidos textos convém tecer, previamente, algumas notas elucidativas sobre a vida do eminente cientista e sobre a procedência dos fragmentos literários utilizados.

\section{O ROMANESCO AIMÉ BONPLAND}

Companheiro de Alexander von Humboldt na célebre viagem às "regiões equinociais" do

CHIORI, J.N.C.; ALVES, F. da S.; DEBLE, A.S. de O. O tipo de Butia yatay (Mart.) Becc. e descrição de uma espécie nova do gênero. Balduinia, Santa Maria, n. 35, p. 1-18, 2012. 
continente americano ${ }^{6}$, expedição cujos resultados bastam para justificar sua merecida fama na história das ciências, Aimé Bonpland abandonou os estudos de gabinete e a vida confortável na Europa ao final de 1816 para se estabelecer em Buenos Aires, atraído pela perspectiva da criação de um Jardim Botânico e Museu de História Natural na cidade ${ }^{7}$.

De 1804, ano do consagrador retorno à França ${ }^{8}$, até a partida definitiva para a América do Sul, Bonpland dedicou-se ao estudo e publicação de parte dos materiais coletados em sua primeira viagem ao Novo Mundo, além de desempenhar-se na superintendência dos parques e jardins do Château de Malmaison, a pedido da Imperatriz Josefina.

Bonpland chegou a Buenos Aires em Janeiro de 1817, juntamente com sua esposa (Adelia Bouchy) e enteada (Emma), passando a exercer a medicina e a coletar espécies nativas, enquanto buscava a viabilização dos projetos que o trouxeram à Argentina. Foi em uma dessas excursões que veio a conhecer, na ilha de Martin Garcia $^{9}$, alguns pés de erva-mate remanescentes de plantio atribuído aos jesuítas ${ }^{10}$, descoberta que veio a influir, decisivamente, nos rumos de sua vida.

6 Referência ao título do relato dessa viagem: HUMBOLDT, A.v.; BONPLAND, A. Voyage aux régions équinoxiales du nouveau continent, fait en 1799 , 1800, 1801, 1802, 1803, et 1804, par Al. de Humboldt et A. Bonpland. Paris, 1820.5 v.

7 Apesar destas perspectivas, Castellanos aponta uma causa mais importante e de natureza familiar: "Bonpland havia casado aos quarenta anos com uma mulher vinte anos mais moça do que ele, a quem havia atendido como médico. Uma "coquine" (mulher libertina), como a chamava Humboldt, que havia sido esposa e mãe, e a quem sua família de La Rochelle (refere-se aos pais de Bonpland) não a queria. Com o andar do tempo lhe era cada vez mais insuportável e o botânico buscava a paz em suas herborizações, logo que havia chegado a Buenos Aires ou em sua ausência nas Missões; enquanto isso ela se foi a Montevidéu, onde deu uma audição "quase" musical, a La Paz, Rio de Janeiro, Jamaica, Nova Iorque e Paris (1826)" (CASTELLANOS, A. Bonpland en los paises del Plata. Revista de la Academia Colombiana de Ciencias, Bogotá, v. 12, n. 45, 1963, p. 62). Sobre a personalidade de Adelia Bouchy, a viajante inglesa Maria
Frustrados os projetos do Jardim Botânico e Museu de História Natural devido a questões políticas, o botânico deixou os familiares, que não voltaria a ver, e partiu para província de Corrientes em Outubro de 1820. Ao chegar às selvas da atual província de Misiones, instalouse em Junho de 1821 na antiga redução jesuítica de Santa Ana ${ }^{11}$, onde "limpou ervais abandonados e os pôs em condições de exploração" 12 . Tratado como espião ${ }^{13}$, foi seqüestrado por um contingente de mais de 400 soldados a mando do ditador Francia ${ }^{14}$ e levado para a margem

Graham, que a conheceu no Rio de Janeiro, refere-se a ela como frívola, intrigante e sem escrúpulos, chegando a afirmar que "não pode haver dúvida que o intento desta mulher era suplantar Mme. de Castro", ou seja, tomar o lugar de Domitila de Castro (Marquesa de Santos) como amante de Dom Pedro I (GRAHAM, M. Escorço biográfico de Dom Pedro I. Rio de Janeiro: Fundação Biblioteca Nacional, 2010. p. 160).

8 Humboldt e Bonpland partiram da América para a Europa a 9 de Junho de 1804, chegando a Bordéus em 03 de Agosto do mesmo ano (CASTELLANOS, 1963. Op. cit., p. 60).

9 Território argentino, a ilha de Martín Garcia situa-se na embocadura do rio da Prata, a escassos $8 \mathrm{~km}$ da localidade uruguaia de Martín Chico. A respeito de sua flora, levantamento recente, dirigido por Lahitte \& Hurrel (1994), não registrou a existência de um único exemplar do gênero Ilex na ilha.

${ }^{10}$ Essa excursão à ilha de Martin Garcia deu-se em 6 de Dezembro de 1818; sobre as referidas plantas de ervamate, consta terem sido levadas por jesuítas de São Javier (CASTELLANOS, 1963. Op. cit., p. 63).

${ }^{11}$ Declaradas Patrimônio Cultural da Humanidade pela UNESCO, em 2011, as ruínas jesuíticas de "Nuestra Señora de Santa Ana" encontram-se cerca de $2 \mathrm{~km}$ da atual cidade argentina de Santa Ana, na província de Misiones.

${ }^{12}$ KRAPOVICKAS, A. Bonpland, sesquicentenario de su muerte. Bonplandia, Corrientes, v. 17, n. 1, 2008, p. 8.

13 Além dessa causa, o botânico Antonio Krapovickas elenca outros dois possíveis motivos para a prisão de Bonpland: "Ao explorar os ervais, ele competiria com o monopólio que os paraguaios tinham do comércio da erva"; além disso, o botânico "se instalou em território que Francia considerava paraguaio e na única rota de comunicação que tinha o Paraguai com o exterior" (KRAPOVICKAS, 2008. Op. cit., p. 8).

${ }^{14}$ José Gaspar Rodríguez de Francia (1776-1840). Doutor em Teologia (Universidad de Córdoba, Argentina), revolucionário e político paraguaio, nomeado "Ditador Perpétuo da República do Paraguai" a partir de 1816. Outro cognome associado ao ditador é o de "El Supremo", título, aliás, utilizado pelo eminente intelectual e historiador paraguaio Augusto Roa Bastos (1917-2005), em sua biografia dessa personalidade histórica. 
direita do rio Paraná, onde ficou retido na aldeia paraguaia de Santa Maria de Fé ${ }^{15}$.

Após nove anos e dois meses de cativeiro, Bonpland deixou o Paraguai a 2 de Fevereiro de 1831. Decidido a instalar-se no Rio Grande do $\mathrm{Sul}^{16}$, passou a dedicar-se à medicina, à criação de gado e, com especial afinco, ao cultivo e exploração da erva-mate, inicialmente em sua propriedade rural do rincão de São João Mirim $^{17}$, ao sul da embocadura do rio Piratini, onde viveu por oito ou nove anos, e após esse período na vila de São Borja.
Em São Borja, Bonpland viveu até 01 de Junho de 1853, data em que se transferiu, definitivamente, para a estância de Santa Ana (Figura 1$)^{18}$, ao sul de Restauración (atual Paso de los Libres, Corrientes), local em que veio a falecer a 11 de Maio de 1858.

Durante a longa permanência em São Borja, Bonpland realizou diversas viagens pelo interior do Rio Grande do Sul ${ }^{19}$ e província de Corrientes, bem como a Montevidéu e Buenos Aires; a capital paraguaia (Asunción), entretanto, somente foi por ele conhecida no ano anteri-

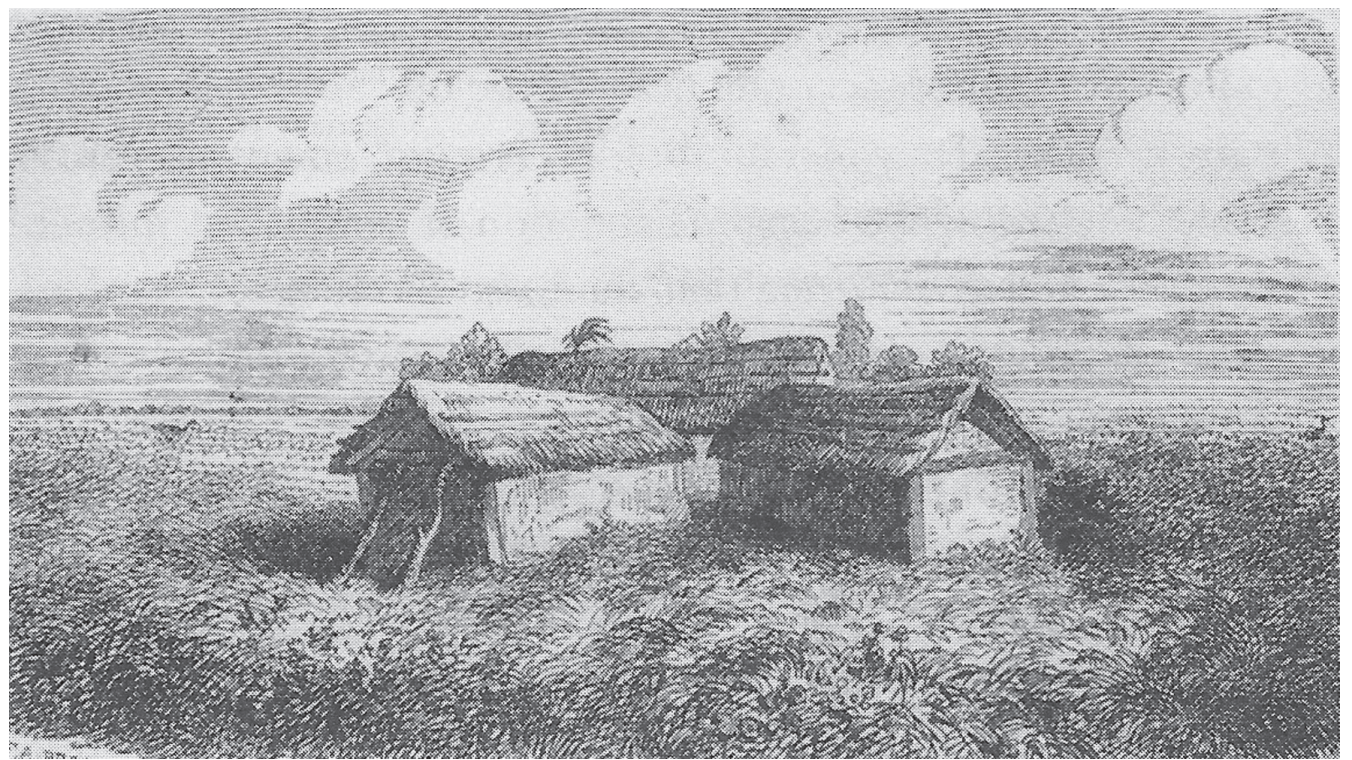

FIGURA 1. Sede da Estância Santa Ana (Corrientes), de Aimé Bonpland, em desenho feito in loco pelo médico e viajante alemão Robert Avé-Lallemant, em Abril de 1858.

${ }^{15}$ Fundada em 1647, Santa Maria de Fe (2647' 6 "S $56^{\circ} 56^{\prime} 24^{\prime \prime O}$ ) situa-se, atualmente, no departamento de Misiones, distando $253 \mathrm{~km}$ ao sul de Assunção.

${ }^{16}$ Ao vir do Paraguai, Bonpland chegou a São Borja na tarde de 14 de Fevereiro de 1831 (BELL, S. A life in shadow. Aimé Bonpland in Southern South America, 1817-1858. Stanford: Stanford University Press, 2010. p. 89$)$.

${ }^{17}$ Foi nessa modesta casa do rincão de São João Mirim que Bonpland recebeu o viajante Arsène Isabelle durante os "dois meses" (dezembro de 1833 e janeiro de 1834) em que o autor de "Viagem ao rio da Prata e ao Rio Grande do Sul" passou em São Borja, indo e vindo da vila (ISABELLE, A. Viagem ao Rio da Prata e ao Rio Grande do Sul. Rio de Janeiro: Livraria Editora Zelio Valverde S.A., 1949. p. 231).
${ }^{18}$ Recebida em enfiteuse em 1838, o título definitivo da propriedade concretizou-se apenas em 25 de Novembro de 1856, graças a um decreto do governador Juan Gregorio Pujol, aprovado pelo congresso provincial de Corrientes (BELL, 2010, p. 202).

${ }^{19}$ Das muitas viagens pela província do Rio Grande do Sul, salienta-se a travessia de São Borja a Porto Alegre, iniciada a 11 de Fevereiro de 1849, e com o objetivo principal de conduzir um rebanho de ovelhas de fina lã de sua propriedade para ser vendida ao dono da "estância de Santa Cruz", situada em área próxima à atual cidade gaúcha de mesmo nome. Além desse objetivo principal, Bonpland também pretendia investigar a presença de ervais na floresta do rebordo do Planalto Meridional e, se possível, enviar por correio o "certificat de vie" a partir da capital gaúcha, documento necessário 
or a sua morte (1857), em viagem de barco a partir da cidade de Corrientes ${ }^{20}$.

Personalidade singular, sob muitos aspectos, Aimé Bonpland teve vida tão romanesca que serviu de motivo para obras literárias, caso da recente "Figura na sombra", do gaúcho Luis Antonio de Assis Brasil ${ }^{21}$. Um dos pontos de difícil entendimento prende-se aos motivos que levaram o botânico francês a não retornar à Europa após o longo cativeiro no Paraguai, preferindo permanecer, definitivamente, na região platina, em locais distantes da alta cultura e do mundo científico, levando uma vida de muita atividade e compromissos materiais, marcada por solidão intelectual e dificuldades de toda a sorte. Esse enigma, dificilmente entendido em tempos hedonistas como os da atualidade, foi, todavia, explicado pelo próprio Bonpland, constando em uma das primeiras biografias do botânico ${ }^{22}$, escrita por Adolphe Brunel $^{23}$ :

para receber os semestres atrasados da pensão que lhe fora concedida pelo governo francês. O manuscrito dessa viagem foi organizado e publicado pela botânica Alicia Lourteig na seguinte obra: BONPLAND, A. Journal Voyage de Sn. Borja a la Cierra y a Porto Alegre. Porto Alegre: Instituto de Biociências, Departamento de Botânica; Paris: Centre Nationale de la Recherche Scientifique, 1978. $175 \mathrm{p}$.

${ }^{20}$ A viagem, a bordo do vapor de guerra "Le Bisson", sob o comando do "Señor Mouchez", estendeu-se de 26 de Fevereiro a 16 de Abril de 1857. Conservado na Biblioteca Nacional do Peru (Lima), o manuscrito foi traduzido do original francês para o espanhol, e publicado no Paraguai em 2006 (CONTRERAS ROQUÉ, J.R.; ROMAÑACH, A.B. El Paraguay en 1857. Un viaje inédito de Aimé Bonpland. Asunción: Servilibro; Universidad Nacional de Pilar, 2006. 222 p.).

21 ASSIS-BRASIL, L.A. de. Figura na sombra. Porto Alegre: L\&PM, 2012. 264 p.

22 BRUNEL, A. Biographie d'Aimé Bonpland, compagnon de voyage et collaborateur d'Al. de Humboldt. Paris: L. Guérin \& Cie.; London: Trubner \& Co.; Montevideo: Lastaria y Cia., 1871. $3^{\mathrm{a}}$ ed. p. 101. Resta informar que a primeira edição dessa obra veio a lume em 1859, poucos meses após a morte do biografado.

${ }^{23}$ Era na casa desse amigo e médico francês, radicado em Montevidéu, que Aimé Bonpland costumava se hospedar quando chegava à capital uruguaia a fim de enviar o "certificat de vie", documento indispensável ao recebimento da pensão anual que o governo francês lhe concedera desde os tempos de Napoleão Bonaparte. A títu-
“Accoutumé à vivre libre, à l'ombre des arbres séculaires de l'Amérique, à entendre le chant des oiseaux, qui suspendent leurs nids audessus de ma tête, à m'asseoir pour voir couler, à mes pieds les eaux pures d'un ruisseau; à la place de tous ces biens, que trouxerais-je, dans le quartier le plus brillant, le plus aristocratique de Paris? Enfermé dans mon cabinet, je devrais travailler jour et nuit pour le compte d'un libraire, qui voudrait bien se charger de la publication de mes oeuvres, j'aurais pour toute compensation le plaisir de voir éclore de temps en temps une rose chétive sur ma croisée. Je perdrais ce que j'apprécie le plus: ma societé de prédilection, mes plants, qui font mon bonheur et ma vie. Non, non, c'est ici que je dois vivre et mourir". ${ }^{24}$

Embora apaixonado pela natureza, Bonpland provou no dia-a-dia que não era um utópico adepto do "L'appel de la forêt", tão ao gosto dos românticos de sua época. Apesar da incessante atividade física e preocupações materiais ao longo de toda a sua vivência na região do Prata, o botânico nunca deixou de lado a curiosidade científica, o desejo de penetrar nos segredos da natureza por meio do estudo e observação, notadamente das plantas, que tanto o atraíam.

\section{OS ARCHIVES INÉDITES}

A predileção de Bonpland pela scientia amabilis explica seu costume de aproveitar as

lo de curiosidade, resta salientar que Adolphe Brunel notabilizou-se na história da medicina sul-americana pelo pioneirismo no uso de anestesia geral com "éter sulfúrico" (01-5-1847).

24 "Habituado a viver ao ar livre, à sombra das árvores seculares, a escutar o canto dos pássaros que suspendem seus ninhos acima de minha cabeça, a olhar correr as águas puras de um riacho; em lugar de todas essas maravilhas, que poderia eu encontrar no bairro mais aristocrático e brilhante de Paris? Encerrado em meu escritório, estaria obrigado a trabalhar dia e noite por conta de um livreiro, tendo por toda a compensação o prazer de ver se abrir de tempo em tempo uma frágil rosa em minha janela. Perderia o que mais quero, minha sociedade de predileção, minhas plantas, que fazem minha alegria e minha vida. Não, não, é aqui onde devo viver e morrer". 
viagens e excursões para herborizar espécimes interessantes, cujas diagnoses eram anotadas no Journal Botanique ${ }^{25}$, enriquecido, não raro, com ilustrações de detalhes morfológicos.

Os fragmentos reproduzidos neste artigo procedem de edição facsimilar de parte do diário botânico, mais precisamente do segundo volume dos Archives Inédites de Aimé Bonpland, publicado pelo Instituto de Botânica e Farmacologia da Faculdade de Ciências Médicas de Buenos Aires em 1924. O histórico desse resgate documental foi assim detalhado por Philippe Foucault, em sua biografia sobre o botânico francês:

"En 1905, Juan A. Dominguez, director de la Facultad de Ciencias Médicas de Buenos Aires, al enterarse de que un alumno llamado Bonpland realizaba sus estudios en la Facultad, lo hizo llamar a su despacho. Éste le declaró que era, en efecto, el nieto ${ }^{26}$ del sabio francés, hijo de Amadito, y que quedaba un gran número de cartas y de manuscritos en Santa Ana donde residia todavía su família. Algunos meses más tarde, Amadito Bonpland en persona se presentaba a Domínguez con un baúl lleno de documentos, los que donaba a la Facultad para ser estudiados y publicados". 27

É do material guardado no referido baú que se exumou para publicação o segundo volume dos Archives Inédites ${ }^{28}$ a ser analisado na

${ }^{25}$ Título original francês (Diário Botânico, em português) do manuscrito de Aimé Bonpland, que foi utilizado como subtítulo na edição facsimilar dos Archives Inédites.

${ }^{26}$ Trata-se de Pompeyo Bonpland, neto do botânico, que graduou-se em Medicina em Buenos Aires. Em segundas núpcias, Aimé Bonpland casou-se com Victoriana Cristaldo, filha de Juan Nicolás Cristaldo, antigo deputado da República Entrerriana e proprietário na região de Yapeju (província de Corrientes). Com Victoriana, Bonpland teve três filhos: Carmen, nascida em 1843; Amado (pai de Pompeyo), nascido em 1845; e Anastácio, nascido em 1847.

${ }^{27}$ FOUCAULT, P. El pescador de orquídeas. Aimé Bonpland, 1773/1858. Buenos Aires: Emecé Editores, 1994. p. 294. sequência, e que inclui as diagnoses de número 2.450 (Novembro de 1849) a 2.884 (Dezembro de 1857). Redigidas em latim, com frequientes anotações em francês e espanhol, essas descrições e anotações variadas sobre plantas seguem a sequência cronológica das expedições, permitindo, inclusive, a definição do local e data de coleta.

\section{REGISTROS DE BONPLAND SOBRE $B U T I A$ NOBLICKII}

Em uma das páginas finais do segundo tomo dos Archives Inédites, Bonpland listou as espécies de palmeiras por ele reconhecidas em Corrientes (Palmiers de Corrientes) e no Paraguai (Palmiers du Paraguay). No caso da referida província argentina constam cinco espécies, sob os nomes de iba puyta, yatay, yatay poñi, palma de sombrero e bocaya (Figura 2). Resta comentar que Bonpland incluiu a "Palma negra" (Copernicia australis Becc.) na coluna das Palmiers du Paraguay, informando que a mesma também se encontra em Corrientes e no Chaco $^{29}$.

A respeito dos nomes listados para Corrientes, iba puyta $^{30}$, palma de sombrero ${ }^{31} \mathrm{e}$

${ }^{28}$ BONPLAND, A. Archives Inédites. Journal de Botanique. Tomo 2. Buenos Aires: Jacobo Peuser Ltda., 1924. (Trabajos del Instituto de Botánica y Farmacologia, Facultad de Ciencias Médicas de Buenos Aires, n. 42).

${ }^{29}$ Em guarani, o termo "carandá" se aplica a espécies de palmeiras (PERALTA, A.J.; OSUNA, T. Diccionario Guarani-Español y Español-Guaraní. Buenos Aires: Editorial Tupã, 1950. p. 39), mais precisamente a espécies de folhas flabeladas, casos de Trithrinax campestris, dito "caranda-i" (carandá pequeno), e Copernicia australis, o caranda-hu (carandá-preto) (BILONI, J.S. Arboles autoctonos argentinos. Buenos Aires: Tipográfica Editora Argentina, 1990. p. 68,69).

${ }^{30}$ Para "iba puyta", o francês agregou, entre parênteses, os nomes comuns "datil", na lista das Palmiers de Corrientes, e "pindo", no caso das Palmiers $d u$ Paraguay.

${ }^{31}$ Para a "palma de sombrero", Bonpland acrescenta que as folhas se prestam para a confecção de chapéus, e que as mesmas são palmadas (palmatis), caráter marcante em Trithrinax campestris, compartilhado, entre as palmeiras de Corrientes, tão somente com a "palma negra" (Copernicia australis), comentada em nota anterior (n. 29). 


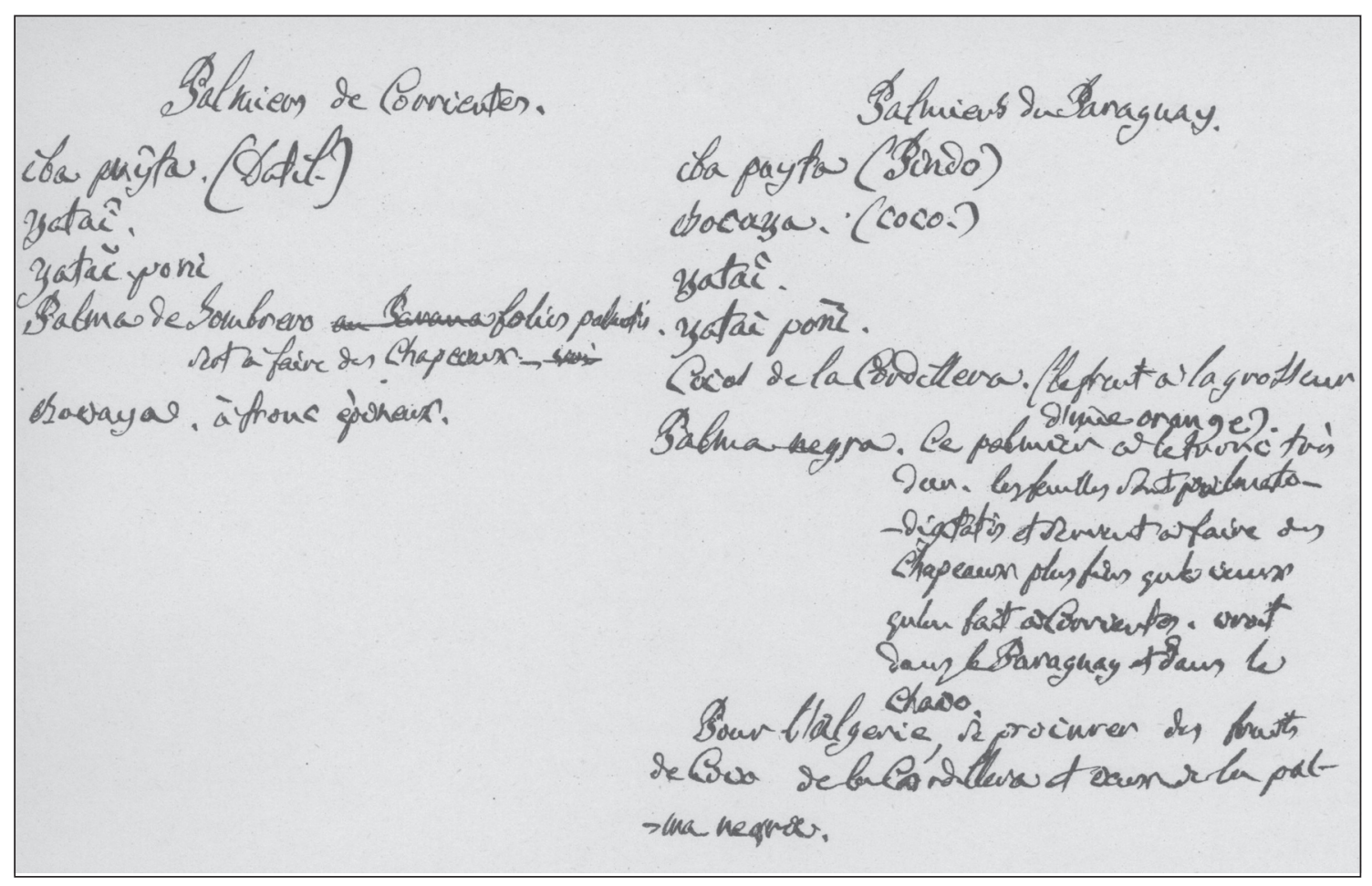

FIGURA 2. Lista das palmeiras de Corrientes (Palmiers de Corrientes) e do Paraguai (Palmiers du Paraguay), constante em uma das páginas finais dos Archives Inédites de Aimé Bonpland.

bocaya $^{32}$ correspondem, indiscutivelmente, a Syagrus romanzoffiana (Cham.) Glassman, Trithrinax campestris Drude \& Griseb. e Acrocomia aculeata (Jacq.) Lodd. ex Mart., respectivamente. Restam para análise os termos yatay e yatay poñi.

Com relação a "yatay", este é o nome comumente atribuído em toda a região para Butia yatay (Mart.) Becc., a palmeira de mais ampla dispersão geográfica na Mesopotâmia argentina e oeste do Uruguai, onde forma extensos palmares, inconfundíveis pelo tom cinzento-azulado da folhagem.

\footnotetext{
${ }^{32}$ No caso de "bocaya", além deste ser o nome ainda hoje utilizado para designar a espécie na Argentina e Paraguai (bocaiúva, no Brasil), Bonpland informa que seu tronco é épineux, ou seja, "espinhoso", caráter morfológico suficiente para a identificação dessa palmeira na flora regional.
}

No segundo tomo de Archives Inédites, a espécie é descrita e ilustrada à folha 36 do manuscrito (n. 2584), com base em coleta realizada em fevereiro de 1854 nos arredores da atual cidade de Concórdia (província de Entre Rios), durante viagem pelo rio Uruguai, de Montevidéu a São Borja. A identificação mais precisa do local é esclarecida no próprio texto do autor, ao mencionar o palmar existente "autour le río Yuquirí Grande et le río Yuquiri Chico" (Figura 3 ), conhecidos tributários do rio Uruguai, situados ao sul da referida cidade entrerriana.

O objetivo prático do desembarque e prolongada estadia nesse ponto da margem direita do rio Uruguai visava a atender a um pedido do cônsul Maillefer ${ }^{33}$, que encomendara sementes

\footnotetext{
${ }^{33}$ Pierre-Daniel Martin-Maillefer (1798-1877). Jornalista e diplomata, Maillefer foi nomeado Cônsul Geral da França em Montevidéu em 1854, no mesmo ano da viagem de retorno de Bonpland a São Borja.
} 


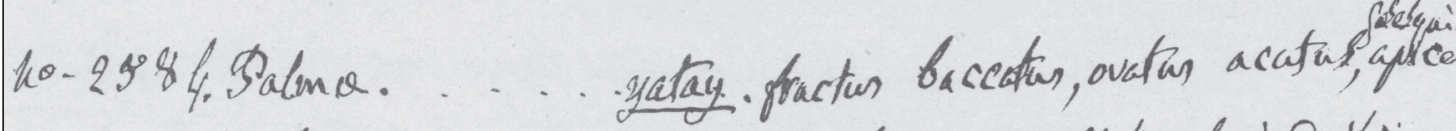

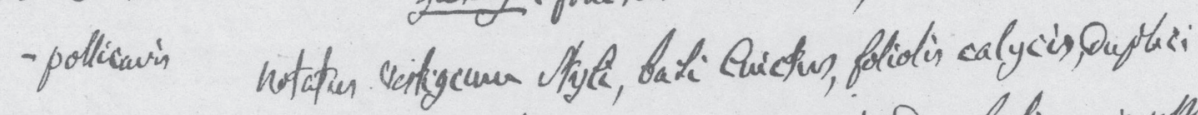

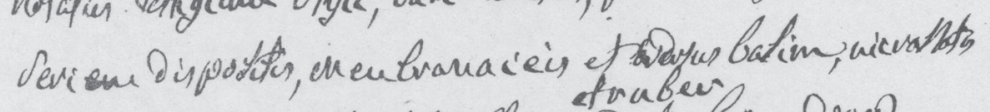

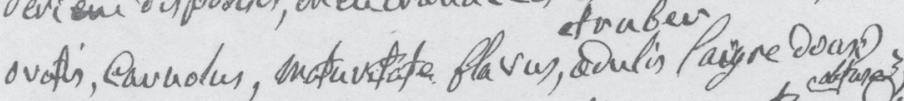

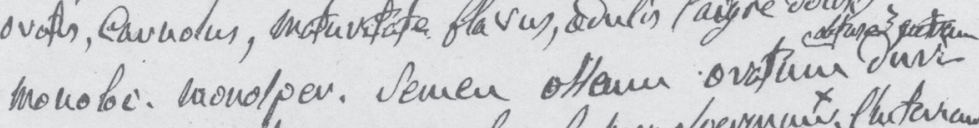

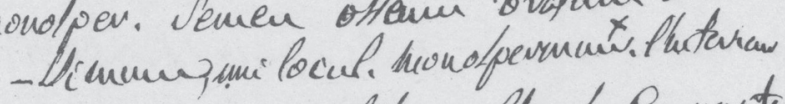

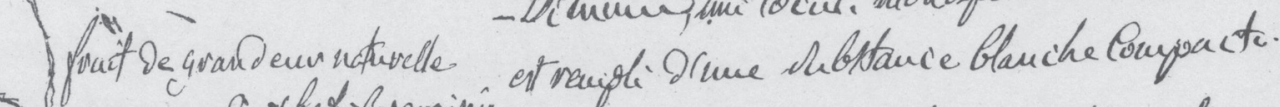

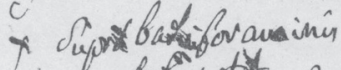

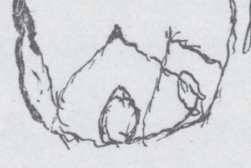

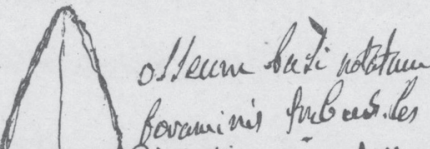

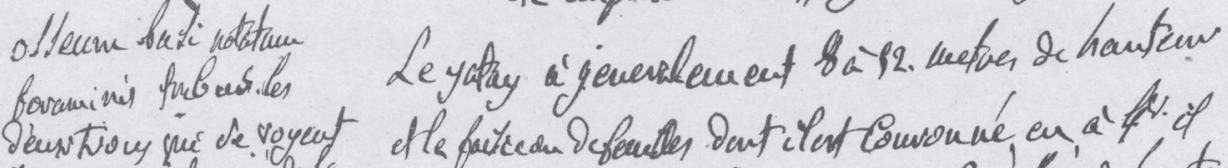

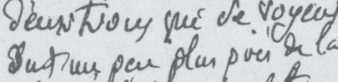

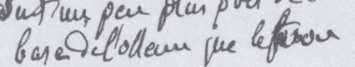
perterear.

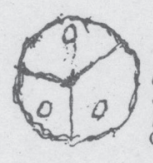

Sectisu hovicuacle nio juant les troin trom Quptocens curfurens sant un penplas ebignes de labale dur postivient. in- preen plen pris

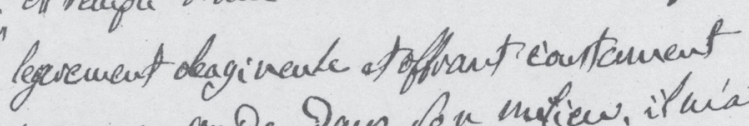
un erpace Trube. Daun Son matiew, it wia

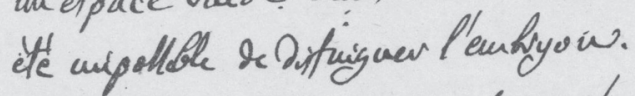

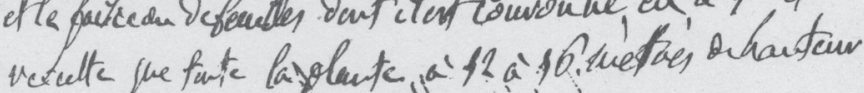

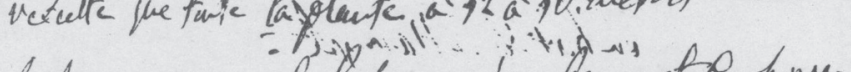

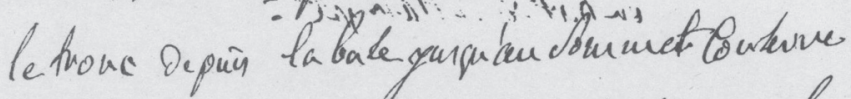

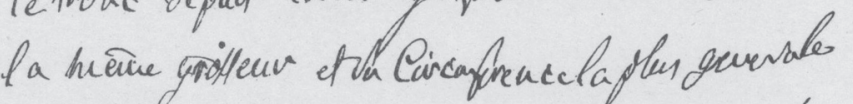

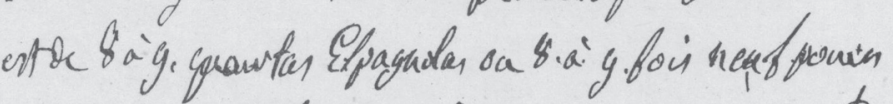

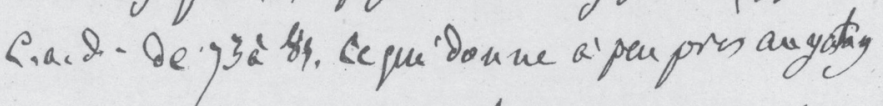

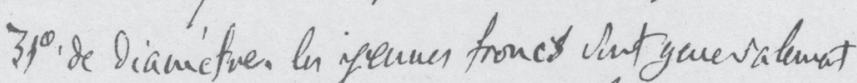

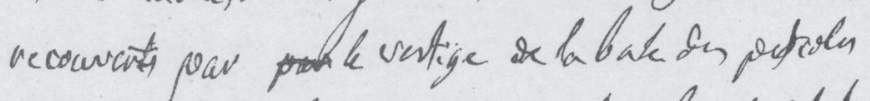

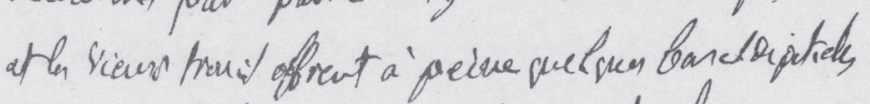

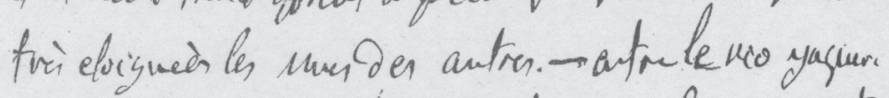

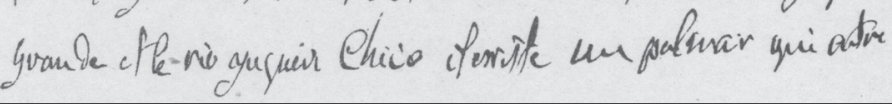

FIGURA 3. Descrição da "Palma yatay", constante à folha 36 do segundo volume dos Archives Inédites de Aimé Bonpland. Conferir a referência aos rios Yuquiri Grande e Yuquiri Chico nas duas últimas linhas manuscritas. 
de árvores interessantes ao botânico, a fim de serem enviadas ao "jardim botânico experimental" de Argel, como "parte de seus esforços no desenvolvimento" daquela colônia ${ }^{34}$. O primeiro embarque, procedente de Concórdia, justamente, foi realizado em março de 1854 , e compreendia "duas caixas cheias de frutos maduros da palmeira yatay", espécie por ele reconhecida como "valiosa". A proximidade entre as datas da coleta n. 2584 (Fevereiro de 1854) e o envio das caixas com sementes (Março de 1854) também comprovam a procedência da amostra em exame. O envio limitado a esta única espécie, por sua vez, foi atribuído por Bonpland ao verão extremamente seco. Para conservar as sementes e prepará-las para a longa viagem oceânica, o botânico recomendou que elas fossem estratificadas em terra nova, em Montevidéu, indicando o jardineiro francês Margat ${ }^{35}$ como pessoa adequada para supervisionar a tarefa. Para o plantio, na Argélia, Bonpland indicou solo arenoso. ${ }^{36}$

Com relação ao "yatay poñi", tema central do presente estudo, constam duas coletas no segundo volume dos Archives Inédites: a de número 2597 (Figura 4), que fecha a folha 38 do manuscrito, a última indicada como "Voyage de Montevideo a Sn. Borja"; e a de número de 2606 (Figura 5), coletada em novembro de 1854 em "Restauración".

Cabe salientar que a primeira destas foi realizada ainda na mesma viagem de Montevidéu a São Borja, explicando-se a informação distinta no cabeçalho da folha seguinte (Sta. Ana de

${ }^{34}$ AArgélia foi declarada "parte integrante da França" pela Constituição Francesa de 1848.

35 Pedro Margat (Versalhes, VII-1807, Montevidéu, 26VI-1890) chegou a Montevidéu em 1838 e, em 1841, fundou o "primeiro estabelecimento de horticultura e floricultura da América do Sul", no "Camino de Burgues". "Único fornecedor de plantas raras" na capital uruguaia, "por muitos anos", atribui-se a ele, entre outras, a "introdução da camélia" (BERRO, M. La Agricultura Colonial. Montevideo: Ministerio de Educación y Cultura; Biblioteca Artigas, 1975. p. 283-284).

36 BELL, 2010. Op. cit., p. 188-190.
l'Uruguay março 1854), à interrupção da viagem e à prolongada estadia de Bonpland em sua estância de Santa Ana, na província de Corrientes. De todo modo, a coleta n. 2597 foi realizada num último desembarque antes da chegada a Santa Ana ou, então, na ida do embarcadouro a sua propriedade. O que importa destacar, no caso, é que essa coleta foi certamente obtida de ponto próximo ao extremo sul do palmar de Butia Noblickii, espécie com distribuição restrita à margem direita do rio Uruguai (província de Corrientes), entre as atuais cidades de Bonpland e Yapeju, aproximadamente.

Stephen Bell, autor que pesquisou detidamente a vida de Bonpland na região platina, esclarece que ao chegar a Santa Ana, na tarde de 22 de Março de 1854, o viajante apressou-se a visitar as plantações feitas antes da ida a Montevidéu, verificando, com um "misto de dor e prazer", que a única em bom estado era a de mandioca; as batatas-doces haviam sido devoradas por veados, e a cerca em torno da "quinta" fora destruída por "inexplicável negligência". Foi nessa oportunidade que o botânico iniciou o plantio do chá da Índia, "procedente do Brasil", do qual ele foi pioneiro na província de Corrientes. ${ }^{37}$

Na diagnose da coleta n. 2597, Bonpland registrou que se trata de "palmeira de pouca altura", fornecendo desenhos em tamanho natural do fruto e semente (Figura 4).

Em novembro de 1854, mês da coleta da "Palma yatay poñi" número 2606 (Figura 5), Bonpland se encontrava em Restauración, antigo nome de Paso de los Libres (Corrientes), conforme indicação no cabeçalho da folha 41 do "Diário Botânico". A respeito dessa viagem, Stephen Bell comenta que o volume de trabalho que aguardava o francês na estância de Santa Ana exigira sua saída de São Borja ainda em setembro, conforme informação constante em carta ao governador Pujol, de Corrientes, pos-

${ }^{37}$ BELL, 2010. Op. cit., p. 191. 


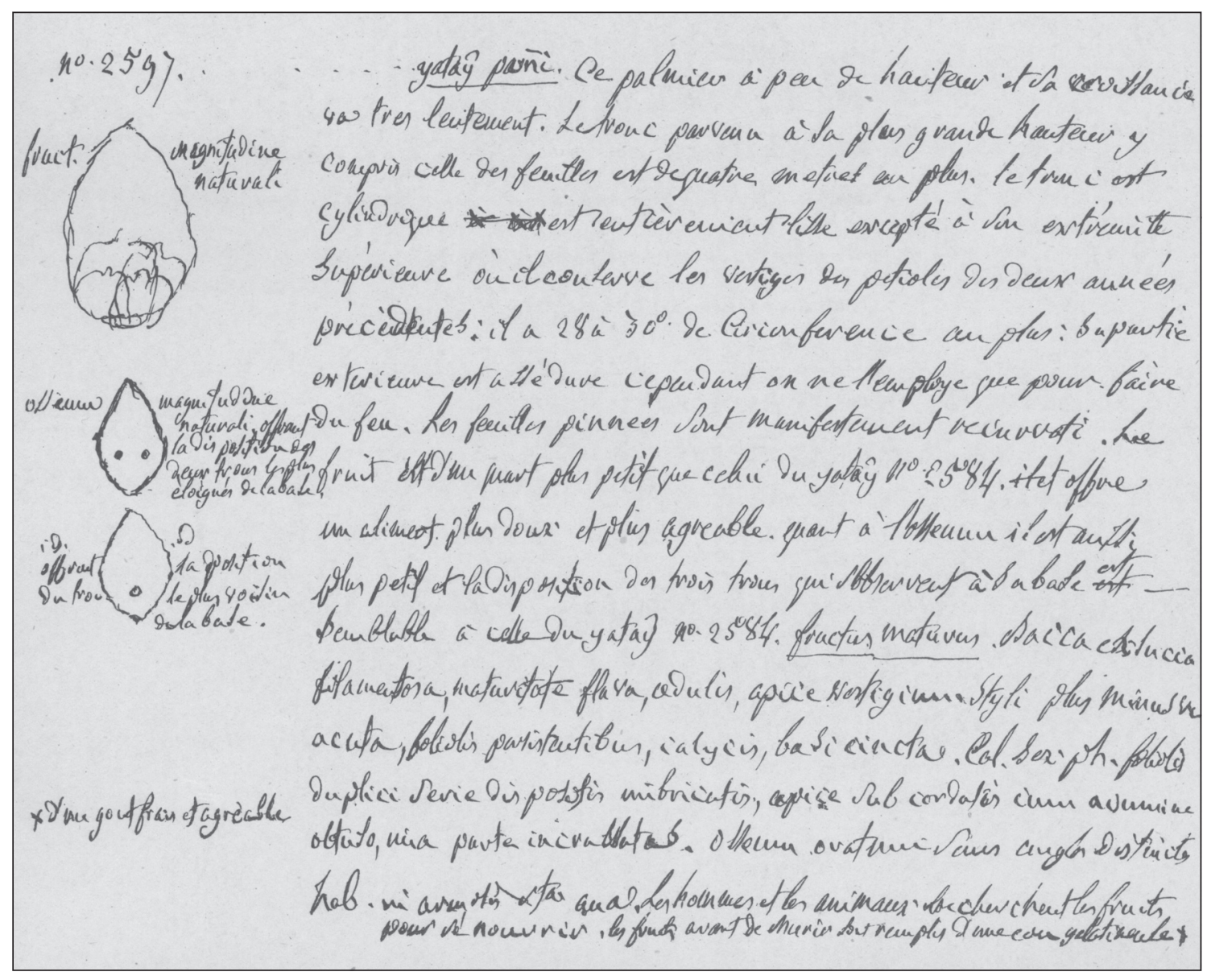

FIGURA 4. Descrição do "yatay poñi”" (n. 2597), ilustrada com desenhos do fruto e semente, constante à folha 38 dos Archives inédites de Aimé Bonpland.

tada a 30 desse mês em Restauración ${ }^{38}$. Resta salientar que o número 2606 do "Diário Botânico", por ser procedente de Paso de los Libres, foi coletado em ponto ao norte da área de distribuição geográfica de Butia Noblickii.

Embora tenha reconhecido o "yatay poñi" como espécie distinta do verdadeiro "yatay", Bonpland não chegou a publicar seus estudos, o que explica a descrição da primeiras destas somente em 2012.

\footnotetext{
${ }^{38}$ BELL, 2010. Op. cit., p. 193.
}

\section{CONCLUSÕES}

Os fragmentos do manuscrito de Aimé Bonpland presentemente analisados demonstram que o botânico francês já reconhecia, em meados do século dezenove, a existência de duas espécies distintas de butiá na província de Corrientes: o "yatay", cujo binômio latino válido é Butia yatay (Mart.) Becc.; e o "yatay poñi”, descrito apenas em 2012, sob o nome de Butia Noblickii Deble, Marchiori, F.S. Alves \& A.S. Oliveira. O nome comum utilizado no presente artigo (Butiá de Bonpland), além de referência geográfica à distribuição natural de Butia 


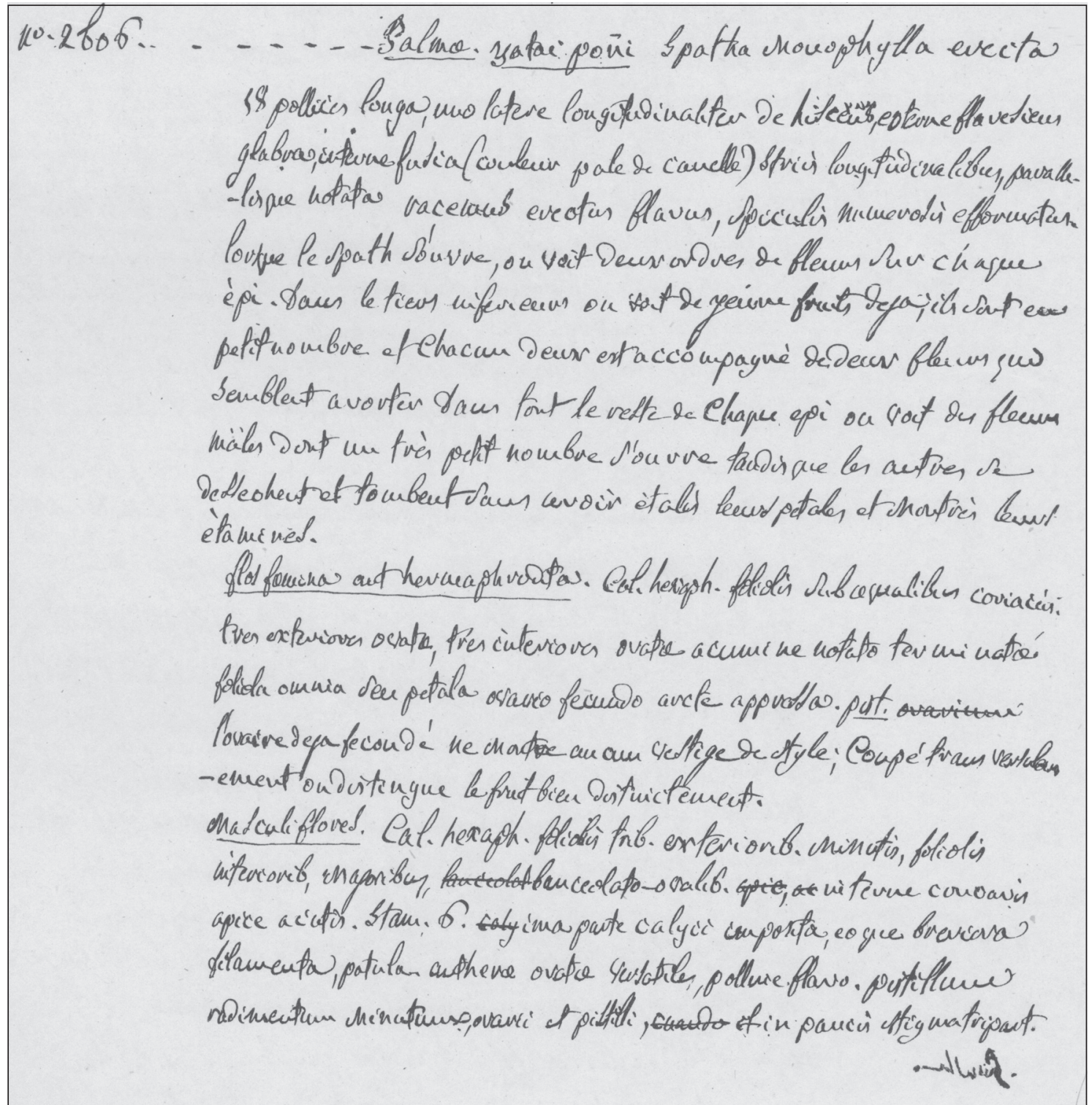

FIGURA 5. Descrição da "Palma yatay poñi" (n. 2606) de "Restauración, Nov. 1854", constante à folha 41 dos Archives Inédites de Aimé Bonpland. 
Noblickii, também se mostra adequado por prestar homenagem ao grande botânico francês que viveu os últimos 41 anos de sua vida na região platina, e foi o primeiro a reconhecer esta espécie botânica como distinta de Butia yatay.

\section{REFERÊNCIAS BIBLIOGRÁFICAS}

ASSIS-BRASIL, L.A. de. Figura na sombra. Porto Alegre: L\&PM, 2012. 264 p.

BELL, S. A life in shadow. Aimé Bonpland in Southern South America, 1817-1858. Stanford: Stanford University Press, 2010. 320 p.

BERRO, M. La Agricultura Colonial. Montevideo: Ministerio de Educación y Cultura; Biblioteca Artigas, 1975. p. 283-284. (Colección de Clásicos Uruguayos, v. 148).

BILONI, J.S. Arboles autoctonos argentinos. Buenos Aires: Tipográfica Editora Argentina, 1990. 335 p.

BONPLAND, A. Journal Voyage de Sn. Borja a la Cierra y a Porto Alegre. Porto Alegre: Instituto de Biociências, Departamento de Botânica; Paris: Centre Nationale de la Recherche Scientifique, $1978.175 \mathrm{p}$.

BONPLAND, A. Archives inédites. Journal de Botanique, Tomo 2. Buenos Aires: Jacobo Peuser Ltda., 1924. (Trabajos del Instituto de Botánica y Farmacologia, Facultad de Ciencias Médicas de Buenos Aires, n. 42).

BRUNEL, A. Biographie d'Aimé Bonpland, compagnon de voyage et collaborateur d'Al. de Humboldt. Paris: L. Guérin \& Cie.; London: Trubner \& Co.; Montevideo: Lastaria y Cia., $1871.3^{\mathrm{a}}$ ed. $185 \mathrm{p}$.
CASTELlanOS, A. Bonpland en los países del Plata. Revista de la Academia Colombiana de Ciencias, Bogotá, v. 12, n. 45, p. 57-85, 1963.

CONTRERAS ROQUÉ, J.R.; ROMAÑACH, A.B. El Paraguay em 1857. Un viaje inédito de Aimé Bonpland. Asunción: Servilibro; Universidad Nacional de Pilar, 2006. 222 p.

DEBLE, L.P.; MARCHIORI, J.N.C.; ALVES, F. da S.; OLIVEIRA-DEBLE, A.S. de. The type of Butia yatay (Mart.) Becc. and description of a new species of the same genus. Balduinia, Santa Maria, n. 35, p. 1-18, 2012.

FOUCAULT, P. El pescador de orquídeas. Aimé Bonpland, 1773/1858. Buenos Aires: Emecé Editores, 1994. 305 p.

GRAHAM, M. Escorço biográfico de Dom Pedro I. Rio de Janeiro: Fundação Biblioteca Nacional, 2010. 352 p. (Cadernos da Biblioteca Nacional).

HUMBOLDT, A.v.; BONPLAND, A. Voyage aux regions équinoxiales du nouveau continent, fait en 1799, 1800, 1801, 1802, 1803, et 1804, par Al. de Humboldt et A. Bonpland. Paris, 1820. 5v.

ISABELLE, A. Viagem ao rio da Prata e ao Rio Grande do Sul. Rio de Janeiro: Livraria Editora Zelio Valverde S.A., 1949. 345 p.

KRAPOVICKAS, A. Bonpland, sesquicentenario de su muerte. Bonplandia, Corrientes, v. 17, n. 1, p. 5-11, 2008.

LAHITTE, H.B.; HURRELL, J.A. Los árboles de la isla Martín Garcia. Buenos Aires: Programas Estructura y dinámica y Ecologia del No Equilíbrio, Comisión de Investigaciones Científicas, 1994. $135 \mathrm{p}$.

PERALTA, A.J.; OSUNA, T. Diccionario GuaraníEspañol y Español-Guaraní. Buenos Aires: Editorial Tupã, 1950. 426 p. 